\title{
Política exterior brasileña y debates sobre la exportación de minerales estratégicos a Estados Unidos (1945-1955)
}

Brazilian Foreign Policy and the discussion about strategic minerals exportation to the United States (1945-1955)

Raquel dos Santos Missagia ${ }^{1}$

\section{Resumen}

Este artículo tiene como tema los Acuerdos Atómicos entre Brasil y Estados Unidos durante el período 1945 a 1955. El foco fue el análisis del contexto interno de la firma de estos acuerdos y sus implicaciones para la política exterior brasileña. El proceso de politización del tema de la exportación de minerales estratégicos a Estados Unidos se entiende en un marco delimitado por actores internos y factores externos. Así, evaluamos e identificamos las posiciones adoptadas por los actores que tuvieron parte en el debate sobre la exportación de estos minerales, buscando trazar una historia del proceso que condujo a la firma de los Acuerdos Atómicos Brasil-Estados Unidos.

Palabras clave: Acuerdos atómicos, Política externa, Minerales estratégicos

\section{Abstract}

This article has as its theme the Atomic Agreements between Brazil and the United States during the period 1945 to 1955 . The focus was the analysis of the internal context of the signing of these agreements and their implications for Brazilian foreign policy. The process of politicization of the issue of the export of strategic minerals to the United States is understood within a framework delimited by internal actors and external factors. Thus, we evaluate and identify the positions adopted by the actors who took part in the debate on the export of these minerals, seeking to trace a history of the process that led to the signing of the Brazil-United States Atomic Agreements.

Recibido: 18 de julio de 2021 Aceptado: 20 de diciembre de 2021 Publicado: 7 de enero de 2022

${ }^{1}$ Doutoranda e Mestre em Estudos Estratégicos pelo Programa de Pós-Graduação em Estudos Estratégicos da Defesa e da Segurança (PPGEST), da Universidade Federal Fluminense (UFF), Niterói, Brasil. Correo electrónico: raqueldos@id.uff.br Twitter @raquelmissagia ID https://orcid.org/0000-0003-2235-7628 
Keywords: Atomic Agreements, Foreign policy, strategic minerals

\section{Introducción}

Comprender los vínculos que unen las políticas internas y externas es un elemento clave en el estudio de los procesos de toma de decisiones. En palabras de Pierre Milza:

La mayoría de las grandes tesis de la historia de las relaciones internacionales contemporáneas, así como numerosos artículos y trabajos básicos que se refieren a la decisión o "no decisión" dan un lugar importante al medio ambiente, lo que permite y lo que no. (Milza, 2003, p. 386)

En este sentido, este artículo busca, a través del análisis de la política interna brasileña, delinear los principales temas que influyeron en la firma de los Acuerdos Atómicos. Si tomamos la política exterior como una representación del "esfuerzo intelectual y pragmático para determinar intereses convergentes y/o divergentes entre diferentes socios" (Altemani, 2005, p. 6), tenemos que ceñirnos a la ecuación que se forma con las variables internas y externos de cada Estado. Las necesidades de la realidad interior deben reconciliarse con las posibilidades exteriores.

De este principio surge la dialéctica política interna y externa, en la que las acciones que realiza el Estado en el plano externo se forman a partir de un consenso que se obtiene a través de las disputas en el plano interno. Así, el interés nacional expresado en la política exterior de un país tiene que ver con las preferencias e intereses del grupo político que gana en los conflictos internos. En esta perspectiva, lo interno y lo externo tienen dimensiones distintas pero complementarias, cuya política exterior busca equilibrar las diferencias entre el marco interno del país con el contexto externo. Así, se asume que las condiciones endógenas y exógenas en la definición de la política exterior brasileña tienen diferentes pesos y, por lo tanto, es necesario identificar cómo actúan estos aspectos en la formulación de sus decisiones y la implementación de sus acciones.

En este sentido, la clave central de este análisis radica en los elementos de conflicto e interés condicionante que orientan la acción estatal en el ámbito internacional. Cabe señalar que el marco temporal aquí analizado, fuertemente marcado por la presencia del Estado como actor preponderante en la integración de Brasil al sistema internacional, deja poco espacio para considerar el papel de la sociedad civil en la formulación de la política exterior brasileña. Sin embargo, no se 
debe perder de vista que el Estado es el actor legítimo para representar los intereses de los ciudadanos y empresas dentro de su territorio a nivel internacional. Así, esta acción hace que el Estado también tenga en cuenta los intereses de la sociedad a la hora de formular su política exterior. Y,

una concepción más adecuada de los determinantes internos de la política exterior y las relaciones internacionales debe enfatizar la lucha política: partidos, clases sociales, grupos de interés (tanto económicos como no económicos), legisladores e incluso la opinión pública y las elecciones, y no solo los funcionarios del poder ejecutivo y arreglos institucionales. (Putnam, 2010, p. 150)

Por ello, se asume que la política exterior brasileña, aun con el Estado como actor con prerrogativas para definirla e implementarla, es el resultado de un entorno que también es responsable de la lucha política interna. Pari passu a esto, es necesario tener en cuenta la capacidad del "poder que tiene cada Estado para imponer sus intereses" (Altemani, 2005, p. 4).

Es un punto de acuerdo en las relaciones internacionales que el sistema internacional es capaz de afectar de alguna manera el comportamiento externo de los Estados. Como resultado de esta afirmación, no se puede ignorar que el sistema bipolar de la Guerra Fría restringió y representó un factor de presión que condicionó las opciones de política exterior brasileña, tanto por variables estructurales como por condiciones circunstanciales. Así, a partir de esta consideración, buscamos acercarnos a la visión de que la política exterior de un país dependiente no es solo un "reflejo de las decisiones del centro hegemónico" (Altemani, 2005, p. 11). De hecho, es el resultado de una interacción entre factores externos e internos, es decir, para examinar la política exterior de un Estado "hay que ir más allá de la mera observación de que los factores internos influyen en asuntos internacionales y viceversa, (...), para buscar teorías que integren ambos ámbitos, teniendo en cuenta las áreas que se entrelazan entre ellos” (Putnam, 2010, p. 151).

En 1951 se produjo la creación del Consejo Nacional de Investigaciones (CNPq), y no fue solo para fortalecer la comunidad científica brasileña, sino también para abordar el desarrollo científico y tecnológico de la energía atómica en Brasil. En la práctica, el $\mathrm{CNPq}$ fue incluido como actor en el debate sobre la exportación de minerales atómicos a Estados Unidos. Con la creación del CNPq en 1951, se reforzó la cuestión de la exportación de minerales estratégicos y, luego de unos meses de negociaciones entre los organismos encargados de atender esta 
cuestión, se llegó a la decisión de que se realizarían nuevas exportaciones. El principal problema que contribuyó al difícil proceso de aprobación del acuerdo fueron los términos que debían incluirse en el ajuste. Entre el CNPq, el Ministerio de Relaciones Exteriores y el Consejo de Seguridad Nacional hubo consenso en que las exportaciones beneficiaron a Brasil, el desacuerdo residió en la tesis de compensaciones específicas, defendida por el CNPq y el CSN. Las compensaciones específicas fueron elaboradas por el almirante Álvaro Alberto, quien afirmó que la exportación de minerales estratégicos solo debe hacerse mediante la transferencia de tecnología para el desarrollo del sector de la energía nuclear en Brasil. Luego de unos meses de negociaciones entre estos organismos, se llegó a un consenso de que se realizaría la exportación. Sin embargo, los términos del convenio firmado por el MRE fueron contrarios a los planteamientos defendidos por el CNPq y el Consejo de Seguridad Nacional (CSN).

El procesamiento del tema de la exportación de minerales estratégicos es fundamental para comprender cómo el $\mathrm{CNPq}$ deja de ser una unidad última de toma de decisiones. El Consejo pasó a ser tratado como un órgano de consulta gubernamental, como miembro de la Comisión de Exportación de Materiales Estratégicos (CEME), que fue creada para operar las ventas de minerales estratégicos y operaba bajo el mando del MRE. El debate sobre las exportaciones contó no solo con la ausencia de consensos entre los órganos competentes, sino también con su polarización en corrientes de pensamiento en boga en ese momento. Así, la división de nacionalistas e internacionalistas, o entregas, impregnó todo el debate sobre los minerales estratégicos. Los primeros se pronunciaron a favor de la tesis de compensaciones específicas, elaborada por el Contralmirante Álvaro Alberto, por otro lado, el segundo grupo apoyó la negociación de minerales como un acuerdo comercial y como máximo que buscaba compensaciones económicas.

Nuestro análisis toma el II Acuerdo Atómico, firmado en 1952, como un hito en la política de exportación de minerales estratégicos. Así, asumimos el 1er Acuerdo como una etapa inicial del tema, en el cual las controversias planteadas culminan con la creación del Comité de Estudio y Fiscalización de Materiales Estratégicos (CEFME). El II Acuerdo agitó el debate sobre minerales estratégicos y fue luego de su firma que el MRE ganó la disputa contra el grupo que se manifestó a favor de la política de compensaciones específicas. En 1954 y 1955, Itamaraty, con el apoyo del CEME, firma nuevos convenios con Estados Unidos para la transferencia de materiales estratégicos. Estos acuerdos preveían la exportación de torio de Brasil y la importación de trigo de Estados Unidos. Los dos últimos acuerdos se ven aquí como la consolidación de la línea de acción de Itamaraty. 
Este artículo tiene como tema el análisis del proceso de toma de decisiones en Política Exterior, buscando dar respuesta al problema de investigación: ¿Por qué el CNPq como organismo creado para abordar el tema de la exportación de estos minerales no puede incidir en el proceso de toma de decisiones? y, en última instancia, ¿se elimina de su posición como unidad de decisión última? Para analizar esta cuestión recurrimos al análisis cualitativo e histórico. Como fuentes primarias se investigaron documentos oficiales, opiniones, informes institucionales, actas, anales y también correspondencia, declaraciones e informes presentes en los archivos personales de científicos, militares y políticos. Trabajamos con fuentes primarias recolectadas del Archivo de la Cámara de Diputados, Centro de Investigación y Documentación de la Fundación Getúlio Vargas (CPDOC - FGV), Archivo Histórico Itamaraty, Archivo CNPq en el Servicio de Documentación y Colección (SEDOC - CNPq).

\section{El paradigma del desarrollo}

Entre 1945 y 1955, el paradigma del desarrollo marcó tanto las relaciones exteriores de Brasil como su política interna. Según Cervo (2008), entre 1930 y 1989 este paradigma se caracterizó por la activación de la diplomacia económica -promoción de la industria ligada a las demandas de la sociedad-, por la posibilidad de "transitar de la servidumbre a la autonomía de decisión con el fin de realizar ganancias recíprocas en las relaciones internacionales "(Cervo, 2008, p. 72), mediante la superación de la desigualdad entre naciones mediante la implementación de un proyecto nacional de desarrollo y consolidación del nacionalismo económico. El modelo de desarrollo a adoptar dividió a líderes, intelectuales y corrientes de opinión pública. En resumen, se presentaron dos modelos como una opción: por un lado, el desarrollo asociado a las fuerzas externas del capitalismo, con vínculos políticos, geopolíticos y económicos con Estados Unidos; y, por otro, el de un sesgo autónomo que defendía el fortalecimiento de la nación por sus propias fuerzas, así como la generación de autonomía política y contaba con una sólida base económica.

Al finalizar la Segunda Guerra Mundial, los impulsos hacia la modernización aumentaron y estos provenían de una sociedad que había cambiado y comenzó a criticar la dependencia y el atraso histórico. Las masas urbanas necesitaban empleo e ingresos; la burguesía nacional estaba ávida de oportunidades comerciales; los militares buscaron formas de brindar seguridad; una parte de intelectuales y políticos había adoptado una mentalidad revolucionaria. Y al mismo tiempo era necesario lidiar con un mundo dividido en comunistas y capitalistas (Cervo, 2008, p. 71-72). 
Es cierto que el aspecto desarrollista de este pensamiento en América Latina partió del grupo de la Comisión Económica para América Latina (CEPAL), de los conceptos de Prebisch a la teoría del desarrollo de Celso Furtado. El grupo de la CEPAL desarrolló una teoría en la década de 1950 que se basó en la experiencia política de Vargas entre 1930 y 1945. Prebisch estableció conceptos de centroperiferia, industria, mercado interno, ingresos salariales, deterioro de los términos de intercambio. Y Celso Furtado se centró en el elemento de la desigualdad tecnológica. Todas estas líneas de pensamiento terminaron por referirse al concepto de poder en las relaciones internacionales y a la "estrategia de guiarse por ventajas comparativas naturales (América Latina) o intangibles (países desarrollados)" (Cervo, 2008, p. 73).

La variable ideológica de la teoría latinoamericana de las relaciones internacionales incluía no solo el desarrollismo, sino también el liberalismo y el occidentalismo como elementos de la cultura democrática. La variable política del paradigma desarrollista, a su vez, se sustenta en la promoción del desarrollo desde un entorno que brinda autonomía para la toma de decisiones, buscando así superar la asimetría capitalista.

Durante décadas, la ideología desarrollista logró la unanimidad en Brasil, pero no logró el entendimiento político. Los líderes e intelectuales brasileños, así como las corrientes de opinión pública, estaban divididos sobre el modelo de desarrollo a implementar. El desarrollo asociado a las fuerzas externas del capitalismo, de estrechos vínculos políticos, geopolíticos y económicos con la matriz del sistema, Estados Unidos, considerado recomendado por Eurico Gaspar Dutra (1946-1950), Castelo Branco (1964-1967), Fernando Collor de Melo (1990-1992) y Fernando Henrique Cardoso (1994-2002). Desarrollo autónomo, esencialmente tocado por las fuerzas de la nación, creador de autonomía política y un núcleo económico fuerte, considerado recomendado por Getúlio Vargas, João Goulart, Ernesto Geisel. (Cervo, 2008, p. 73-74)

Estas dos corrientes de pensamiento movilizaron a grupos dentro de la sociedad brasileña y generaron diferentes interpretaciones de las demandas de la sociedad. Cervo afirma que la interpretación de los intereses nacionales de los desarrollistas se opera desde el concepto de una sociedad compleja, que está en transformación, hacia el progreso económico. Y es con Vargas que se estableció el deber del gobierno de poder brindar un ambiente propicio a las necesidades de empresarios, agricultores, industriales, trabajadores, campesinos, militares, 
científicos y otros grupos. Allí se puede ver la implementación de los múltiples intereses nacionales, en los que le toca a la diplomacia equilibrar la suma de diferentes intereses, que en ocasiones se colocan en lados opuestos.

El desarrollismo reemplazó el vector de apertura del mercado con la búsqueda del desarrollo a través de la política exterior. Es de destacar que, a pesar de que el desarrollo es un concepto sociológico complejo que engloba a los sectores económico y social, en la práctica los tomadores de decisiones estaban restringidos a la industrialización y el crecimiento económico. La industrialización era un elemento clave porque se creía que a través de ella se cumplirían las demandas de una sociedad compleja, y empujaría al conjunto hacia el capitalismo moderno y la superación del atraso histórico. En este sentido, la política exterior ocupaba un lugar especial, ya que cumpliría con los requerimientos de este desarrollo, aportando tres bases de apoyo a los esfuerzos internos desde el exterior: capital que complementaría el ahorro nacional, la ciencia y la tecnología, y los mercados externos, moviendo así desde la sustitución de importaciones hasta las exportaciones (Cervo, 2008, p. 75).

El período aquí estudiado, a excepción del interregno del gobierno de Dutra, se ubica en la fase de implantación de la gran industria de transformación asociada a la empresa extranjera. La asociación con capital extranjero será objeto de permanente controversia, principalmente por la cuestión del grado de apertura en el largo plazo. A pesar de esta polémica, la apertura del sistema productivo y del mercado consumidor se entendió como una variable de decisión funcional, es decir, el grado de apertura se evaluó por el impacto que tendría en el desarrollo. Así, es posible ver que el gobierno podría dar más protección a un sector de actividades, a un grupo o al conjunto del sistema productivo, buscando contribuir al crecimiento a través de empresas nacionales o extranjeras.

El paradigma del desarrollo tuvo un fuerte impacto en la formación nacional, y el principal fue la búsqueda de romper los lazos de dependencia. Sin embargo, uno de los rasgos más fuertes de esta corriente de pensamiento fue cómo "los pensadores brasileños, si bien enfocaron su reflexión en el desarrollo de la nación, no coincidieron en la forma de conceptualizarla y, lógicamente, en los mecanismos para lograrlo" (Cervo, 2008, p. 13).

\section{Proyectos económicos para Brasil en la década de 1950}

El desarrollismo tiene su origen exactamente en este período de 1930 a 1945 . A partir de la crisis económica internacional, sus repercusiones internas en el sistema económico brasileño y la centralización política llevada a cabo por la Revolución de 
1930, se enumeran como los principales factores explicativos del surgimiento de esta ideología económica. Las bases del desarrollismo residen en el sector privado, a través de entidades que buscaron implementar una estrategia de industrialización planificada; y en el sector público, que, principalmente entre 1930 y 1945, formó y consolidó una serie de organismos administrativos, integrados por técnicos civiles y militares que tenían alcance nacional y buscaban resolver los problemas del país. Esta experiencia hizo que estos técnicos reflexionaran sobre la realidad interna de Brasil de manera integrada, conduciendo a la formulación del pensamiento desarrollista (Bielchowsky, 2000, pág.78).

Según Bielschowsky, partiendo del concepto de desarrollismo es posible identificar cinco corrientes de pensamiento económico, en las que se encontrarían la mayoría de los economistas e intelectuales que conformaron el debate económico entre 1945 y 1964. Este autor define: "Desarrollismo, [...], es el 'proyecto' para superar el subdesarrollo a través de la industrialización integral, a través de la planificación y el apoyo decisivo del Estado" (Bielchowsky, 2000, p. 33). Las cinco corrientes de pensamiento son: neoliberal; el de desarrollo, que se subdivide en el sector público "nacionalista", el sector público "no nacionalista" y el sector privado; y el socialista.

A grandes rasgos, la corriente neoliberal se puede definir en contraposición a las desarrollistas, y está compuesta por economistas que creían en la necesidad de mantener la prioridad del libre movimiento de las fuerzas del mercado como medio para lograr la eficiencia económica. Sin embargo, una de sus principales características fue la oposición u omisión de las propuestas de desarrollo. Los economistas de esta corriente creían en el establecimiento de condiciones de equilibrio monetario y financiero que garantizaran la maximización de la eficiencia de los mecanismos de mercado. Buscando lograr este equilibrio, aceptaron que el gobierno debería realizar alguna intervención para remediar los desajustes, diagnosticados como eventos comunes en las economías subdesarrolladas. Sin embargo, las políticas monetaria, fiscal y cambiaria deben guiarse por los parámetros estipulados por los teóricos y administradores de los bancos centrales de los países industrializados. Debería haber equilibrio en los presupuestos gubernamentales, al igual que la oferta monetaria estaría estrictamente controlada. El principal determinante de la economía sería el mecanismo de precios.

Para este grupo, el capital extranjero era una necesidad indispensable y todas las limitaciones impuestas por el gobierno a la "circulación internacional de capital, moneda y productos debían reducirse al mínimo” (Skidmore, 2010, p. 122). Fue defendido por la libre acción del capital extranjero sin control del Estado. 
"Políticamente hablando, este hilo correspondía a las" banderas "de la UDN y sectores representados por ella" (Mendonça, 1986, p. 69).

Los neoliberales Eugênio Gudin, Octávio G. de Bulhões, Dênio Nogueira y Daniel de Carvalho son los principales representantes de esta corriente. La Fundación Getúlio Vargas (FGV), el Consejo Nacional de Comercio, la Asociación Comercial de São Paulo y el Consejo Nacional de Economía (CNE) fueron los principales centros de actividad de estos economistas.

Bielschowsky (2000) divide la corriente del desarrollo en tres líneas. La rama desarrollista del sector privado estaba compuesta por economistas que tenían una postura antiliberal y desarrollista. Aceptaron la intervención estatal como una forma de ayudar a la acumulación privada y tuvieron diferentes posiciones sobre el grado de participación estatal en este proceso. En cuanto a la participación de capital extranjero, no hubo una postura uniforme. La Confederación Nacional de la Industria (CNI) y Fiesp fueron los principales lugares donde se pudo encontrar esta línea de pensamiento. Sus principales representantes fueron J. P. de A. Magalhães y Nuno F. de Figueiredo.

Los economistas de la vertiente desarrollista "no nacionalista", ubicados en el sector público, favorecieron el apoyo estatal a la industrialización, aunque cuando hubo una disputa con el sector privado, favorecieron a este último. Como los neoliberales, tenían predilección por las políticas de estabilización monetaria. Pero aun así, impidieron que esta política económica afectara inversiones fundamentales. Roberto Campos, Ary Torres, Lucas Lopes y Glycon de Paiva se destacaron como economistas de esta corriente de pensamiento. Sus áreas principales fueron la Comisión Conjunta Brasil-Estados Unidos y el Banco Nacional de Desarrollo Económico (BNDE).

A pesar de que este grupo era numéricamente menos importante, tenía una gran expresión intelectual. El centro de poder de este grupo era la codirección del BNDE, compartida con los nacionalistas desarrollistas, y no formaba un núcleo de producción intelectual. La posición de sus miembros oscilaba constantemente entre neoliberales y nacionalistas. Por un lado, expresaron su preferencia por la iniciativa privada nacional y extranjera en los servicios públicos y la minería, y por otro, mostraron una gran empatía por los proyectos de industrialización planificados. La Comisión Mixta, disuelta en 1953, fue el lugar donde confluyó esta corriente.

En el sector público había una rama de economistas "nacionalistas". Estos defendieron inversiones estatales en sectores considerados estratégicos para la industrialización, es decir, energía, minería, transporte, telecomunicaciones e industrias básicas. Se opusieron a las políticas de estabilización por temor a que el país entrara en recesión. "El término 'nacionalista' es apropiado, ya que la propuesta 
alternativa a la estatal era la de inversión extranjera, dada la frágil estructura del capital nacional" (Bielchowsky, 2000, pág. 34). Celso Furtado, Rômulo de Almeida, Américo B. Oliveira y Evaldo B. Lima fueron los economistas más destacados del pensamiento desarrollista nacionalista. El BNDE, la Asesoría Económica Vargas, el Club de Economistas, la CEPAL y el Instituto Superior de Estudios Brasileños (ISEB) fueron los principales lugares donde circularon representantes de esta rama.

El ISEB, creado en 1955 por el Ministerio de Educación y Cultura, fue el principal portavoz del discurso del desarrollo nacional. De hecho, ISEB nació del Instituto Brasileño de Economía, Sociología y Politica (IBESP). El IBESP fue el resultado de una serie de encuentros que un grupo de intelectuales de Río de Janeiro y São Paulo realizaron a fines de cada mes en el Parque Nacional de Itatiaia en 1952 y 1953, resultando en la publicación de la revista Cadernos de Nosso Tempo (Bielchowsky, 2000, p. 369), entre 1953 y 1956. El objetivo de este instituto era pensar en el desarrollo del país a partir de sus problemas, y proponer soluciones para superar el atraso crónico de la nación.

Con una diversa composición de intelectuales, como Hélio Jaguaribe, Nelson Werneck Sodré, Candido Mendes y Roland Corbisier, entre otros, sus acciones se desarrollaron principalmente a través de la promoción de cursos, conferencias y encuentros en los que "la matriz de pensamiento responsable de la movilización fue difundido para el 'progreso' del país” (Mendonça, 1986, pág. 71). El ISEB se convertiría en un actor clave en la creación de ideologías que legitimaron las transformaciones económicas vividas por el país en ese período.

Esta corriente, también denominada nacional-desarrollista, cobró gran impulso con la publicación de trabajos de la CEPAL, que buscaban "diagnosticar los males y remedios para el problema del subdesarrollo" (Mendonça, 1986, p. 72). Para Skidmore, "los orígenes de esta visión en Brasil se encuentran en el nacionalismo económico de los lugartenientes y, más tarde, en los esfuerzos estatales por industrializar el Estado Novo" (2010, pág.123). Skidmore afirma que esta corriente propugnaba una nueva estrategia, en la que el país debería buscar una economía mixta. El sector privado debería recibir inversiones y nuevos incentivos, el Estado haría mayores intervenciones a través de empresas estatales y mixtas públicoprivadas. El objetivo era eliminar los cuellos de botella y garantizar las inversiones en áreas en las que el sector privado no tenía intereses ni capital para invertir. Esta corriente admitió la posibilidad de inversiones extranjeras, pero estas deben hacerse con la máxima regulación por parte del gobierno brasileño.

La fórmula nacionalista-desarrollista fue propuesta por un grupo pequeño pero variado. Su denominador común fue un fuerte 
nacionalismo. Muchos oficiales del ejército, por ejemplo, sintieron que Brasil solo podría convertirse en una gran potencia si desarrollaba su industria. Además, la seguridad nacional de Brasil requería que la explotación de recursos naturales como combustible, potencial hidroeléctrico y reservas minerales no cayera en manos extranjeras. (Skidmore, 2010, p. 123)

En 1951, el desarrollismo nacional estaba en su infancia, sin embargo durante el gobierno de Vargas esta tendencia sería la más extendida y comprendida, atrayendo a una generación de jóvenes tecnócratas e intelectuales. Los representantes de este grupo defendieron que se haga un esfuerzo para acelerar la industrialización, solo así Brasil dejaría atrás su condición de país atrasado y alcanzaría un nivel de vida digno de un país moderno.

La corriente socialista estaba compuesta por intelectuales y economistas que tenían alguna conexión con el Partido Comunista Brasileño. Los socialistas también abogaban por la industrialización y la intervención estatal, y hasta cierto punto también eran desarrollistas, pero su objetivo era el paso al socialismo. En este sentido, la industrialización fue una etapa para el desarrollo de las fuerzas productivas necesarias para la transición al socialismo. El pensamiento de esta corriente se organiza tanto desde la perspectiva de la revolución como de la lucha contra el imperialismo. Esta visión "subordinó todo el pensamiento económico de la corriente socialista, incidiendo no sólo en el contenido de ese pensamiento, sino también en la forma en que se expresaba, lo que acentuaba sus diferencias en relación al desarrollismo nacionalista" (Bielchowsky, 2000, pág. 34). El principal núcleo de acción de esta corriente, además del PCB, fue el ISEB. Sus exponentes fueron Caio Prado Júnior, Nelson W. Sodré, Alberto Passos Guimarães y Aristóteles Moura.

Para Skidmore, esta corriente era una forma de nacionalismo radical, ya que en realidad esta posición defendía que la estructura económica y social brasileña se basaba en la explotación y, por tanto, se necesitaba un cambio radical. Para los radicales, el subdesarrollo del país tiene sus raíces en la alianza entre inversores privados y gobiernos capitalistas. Esta alianza significó que Brasil estaba destinado a jugar un papel subsidiario en el escenario internacional, como mero exportador de materias primas e importador de manufacturas. De esta definición, cualquier iniciativa de industrialización estaría condenada al fracaso.

En general, es necesario enfatizar que estas posiciones no eran fácilmente identificables y más bien constituyen una posición analítica presentada por un pequeño grupo de escritores y propagandistas. En la práctica, estas corrientes no 
eran excluyentes, "un mismo individuo, o sector económico, podía tomar prestado el lenguaje de cualquier otro, o de otros dos, o de los tres sin comprometerse con toda la fórmula" (Skidmore, 2010, p. 125).

A pesar de las disputas que se produjeron entre estas corrientes económicas, en política sería la corriente nacionalista-desarrollista la que lograría más éxitos. El sentido de nacionalismo-desarrollismo en el proyecto Vargas se caracterizaría principalmente por la creación de un país desarrollado, a través de la industrialización intensa y el intervencionismo estatal en la economía (Mendonça, 1986, p. 70). En este sentido, los debates sobre las exportaciones de minerales estratégicos a Estados Unidos bordean los debates sobre las tendencias de desarrollo en el período analizado por esta investigación.

\section{El Primer Acuerdo Atómico}

Cuando se firmó el I Acuerdo Atómico, Vargas aún ocupaba la presidencia, pero el Estado Novo ya mostraba las primeras señales de que iba a caer. Los opositores al régimen pudieron explotar la contradicción creada por la entrada de Brasil en la Segunda Guerra Mundial. La presencia de Brasil en la guerra junto con las democracias reveló el régimen autoritario bajo el cual vivía Brasil. Según Carone, "la caída del Estado Novo es un proceso lento que comienza con la Ley Adicional $\mathrm{N}^{\circ}$ 9, del 28 de febrero de 1945, y finaliza con la destitución de Getúlio Vargas, el 29 de octubre del mismo año" (Carone, 1985, pág.9). La Ley Adicional N 9 comprometió al gobierno a convocar elecciones presidenciales. Lo que sucedió fue que, en este período de tiempo, el país atravesó un intenso malestar social y político. Las principales cuestiones que ocuparon a los diferentes grupos fueron problemas básicos e inmediatos de amnistía, elecciones, desenfreno y la Asamblea Constituyente. Todas estas cuestiones abrieron espacio para el aumento de divergencias entre situacionistas y oposicionistas. Ante este marco de grandes tensiones internas, el I Acuerdo Atómico pasó desapercibido.

En septiembre de 1945, la Fundación Getúlio Vargas promovió un Simposio sobre Energía Atómica, en Río de Janeiro, durante el cual el geólogo Othon H. Leonardos reveló que la presencia de uranio en suelo brasileño era pequeña. Ante esto, el profesor de la Escuela Politécnica de la Universidad de São Paulo (EPUSP), Luiz Cintra do Prado, llamó la atención sobre la necesidad de investigaciones en física nuclear, orientadas al uso del torio en la producción de energía nuclear. Cintra do Prado, argumentó que,

la obtención de un isótopo de uranio (susceptible de dar lugar a una reacción en cadena), a partir del torio, mediante reacciones nucleares 
análogas a las que tienen lugar en la producción de plutonio, a partir del uranio 238. Esta opinión era correcta. Más tarde se supo que el torio podía de hecho transmutar en uranio 233, capaz de fisionarse. (Motoyama; Garcia, 1996, p. 26)

Lo que parecía ser una posibilidad de investigación para los científicos brasileños, era una realidad para los norteamericanos. No fue una coincidencia que, a principios de julio de 1945, Valentim Bouças informara al ministro de Relaciones Exteriores, Leão Veloso, que había negociado con el secretario de Estado estadounidense Edward Stettinius un acuerdo de exportación para la monacita brasileña. Estas conversaciones se llevaron a cabo durante la Conferencia de Chapultepec y, poco después, el 10 de julio, se firmó en secreto el Acuerdo, que prevé la venta exclusiva a Estados Unidos de 3.000 toneladas anuales, por tres años y prorrogables hasta por diez tres años consecutivos. En ese momento, el bando brasileño no conocía el interés real de su aliado en el Monazite, y la justificación que dio fue que constituía material estratégico para la guerra. En los Estados Unidos, el proyecto de Manhattan para la producción de la bomba atómica se desarrolló bajo el máximo secreto. A los pocos días de la firma del Acuerdo, el 16 de julio de 1945, se llevaría a cabo la primera prueba con la bomba atómica en Jounado del Muerto, en el desierto de Alamogordo. La embajada brasileña no sabía de esta prueba, pero con el fin de la guerra el "gran secreto" salió al público con la explosión de bombas en las ciudades de Hiroshima y Nagasaki.

El fin del Estado Novo inauguró la Tercera República (1945-64), y se inició un período democrático que abrió la posibilidad de impugnar los actos del gobierno (Schimitt, 2005, p. 8). El período que comenzó con la caída de Vargas puede describirse como la primera experiencia de democracia representativa en la historia brasileña, confirmada por la Constitución de 1946, ya que conocieron el potencial del torio presente en la monacita. Al mismo tiempo, en el campo de la política, aparecieron representantes del gobierno y comenzaron a cuestionar el Acuerdo. Según Dagoberto Salles (Salles, 1958, p. 86), a medida que los órganos encargados de salvaguardar los intereses brasileños se dieron cuenta de los términos del Acuerdo, comenzaron a cuestionar su viabilidad. Así, el 27 de agosto de 1946, la secretaría del Consejo de Seguridad Nacional (CSN) envió un memorando secreto al presidente Dutra, proponiendo que se denunciara este pacto.

Posteriormente, el diputado José Maria Crispim propuso el Proyecto de Ley $N^{\circ} 418 / 47$, que prohíbe la exportación de monacita. En el mismo camino estuvo la iniciativa de crear el Comité de Estudios y Supervisión de Materiales Estratégicos (CEFME), que funcionó con la Secretaría General del Consejo de Seguridad 
Nacional desde el 20 de febrero de 1947. Este Comité también contó con el apoyo del Departamento Nacional de Producción Mineral (DNPM). El CEFME buscaría conciliar los intereses de quienes estaban en contra de la política del Ministerio de Relaciones Exteriores, con los de quienes estaban a favor (Dhenin, 2010, p. 71). La Comisión estuvo integrada por las siguientes personas: Coronel Bernardino de Mattos y Othon Leonardos -ambos del Consejo de Minas y Metalurgia-, Joaquim Costa Ribeiro, Marcello Damy Santos y Alberto Ericksen, y por el Capitán de Corbeta José Cruz Santos de la DNPM (Brasil, 1953). La propuesta principal de este organismo fue remitida por su presidente, Bernadino de Mattos, al CSN. Estableció la estipulación de cuotas anuales fijas para la exportación de monacita, ilmenita y zirconita. La creación de CEFME, a pesar de no haber logrado limitar las exportaciones de minerales estratégicos, fue percibida como uno de los primeros intentos de instituir una política de minerales fisionables. El ambiente interno mostró fuertes rastros de un clima nacionalista dentro de una porción significativa de la población brasileña.

Cuando comenzó a acercarse la fecha límite para el fin del primer período de tres años de vigencia del 1er Acuerdo, Estados Unidos se manifestó mediante nota el 21 de octubre de 1947, manifestando que tenía interés en extender el acuerdo. Sin embargo, ya no fue posible llevar a cabo la renovación en los términos acordados en 1945. El ministro Raúl Fernandes "consideró que el Ejecutivo no tenía los medios para garantizar la exclusividad exportadora que otorga el convenio a EE.UU. superviniendo había hecho imposible mantener la exclusividad vigente”. Las conversaciones entre Brasil y Estados Unidos continuaron a través de Itamaraty y la Embajada de Estados Unidos, pero las dificultades impuestas por el CSN hicieron imposible la renovación del Acuerdo.

La falta de bases para sustentar la renovación del Acuerdo hizo que no fuera renovado. Aun así, esto no impidió que continuaran las exportaciones. Los siguientes datos lo demuestran:

Año 1945. Exportación (en ton.): 1.031

Año 1946. Exportación (en ton.): 1.250

Año 1947. Exportación (en ton.): 2.000

Año 1948. Exportación (en ton.): 1.605

Año 1949. Exportación (en ton.): 2.255

Año 1950. Exportación (en ton.): 1.000

Año 1951. Exportación (en ton.): 1.000 
Lo que se observa es que entre 1945 y 1947, período en el que estuvo en vigencia el I Acuerdo, se exportaron a Estados Unidos 4.281 toneladas de monacita. En el período de 1948 a 1951, podemos ver que se exportaron un total de 5.860 toneladas. A pesar de la no renovación del acuerdo, la monacita brasileña continuó siendo exportada, incluso siendo contrabandeada y cargada como lastre de los barcos (Dhenin, 2010, p. 66).

Al no renovar el Acuerdo, Estados Unidos inició negociaciones para firmar un acuerdo para aumentar el conocimiento de las reservas de minerales fisionables en suelo brasileño. La falta de técnicos capacitados en el área de Ciencia y Tecnología contribuyó a justificar el ajuste de 1948. Varios geólogos norteamericanos recorrieron el territorio nacional cartografiando y ampliando el conocimiento de nuestras reservas minerales atómicas y localizando nuevos depósitos. El 26 de noviembre de 1948 se concluyó un Acuerdo Administrativo entre Brasil y Estados Unidos entre el ministro interino Hildebrando Acioli y el embajador estadounidense Hershell V. Johnson. El programa de investigación de este convenio buscaba continuar:

Al programa de cooperación, establecido en 1940, para el estudio de los recursos minerales en Brasil, a través de estudios geológicos, ubicación de depósitos, pruebas, procesamiento y proyectos relacionados, el Acuerdo estableció un entendimiento íntimo entre nuestro Departamento Nacional de Producción Mineral, el Departamento de Agricultura, la Oficina de Minas y el Servicio Geológico del Departamento del Interior de los Estados Unidos. (Guilherme, 1957, p. 103)

Toda la investigación resultante de este programa de cooperación era confidencial y estaba destinada al uso exclusivo de ambos gobiernos, y los resultados serían difundidos con la aprobación de Brasil y Estados Unidos. Sin embargo, pronto se conoció información sobre los nuevos depósitos en Estados Unidos, lo que provocó que empresarios norteamericanos solicitaran varias concesiones de exploración. Y, en 1952, el geólogo estadounidense Max G. White encontró la presencia de uranio en los depósitos de Poços de Caldas (MG). Luego, en 1953, Vargas autorizaría la instalación de una planta de procesamiento en el sitio a través de un contrato con la soviética francesa de Produits Chimiques des Terres Rares. 


\section{La Política Nuclear Brasileña, el CNPq y Álvaro Alberto}

En 1946, Álvaro Alberto da Motta e Silva fue designado por la Armada de Brasil para ser su representante en la delegación brasileña ante la Comisión de Energía Atómica de la ONU (CEA). Álvaro Alberto (1889-1976) es identificado por la historiografía como uno de los grandes defensores del desarrollo de la energía nuclear en Brasil.

Álvaro Alberto estudió en la Escola Naval, estudió ingeniería en la Escuela Politécnica de Río de Janeiro y completó sus estudios en la École Centrale Technique, en Bruselas. Fue instructor y luego profesor del Departamento de Físico-Químico de la Escola Naval. Pólvora y explosivos, química y metalurgia fueron las materias que impartió. En 1917 fundó una empresa de explosivos que presidió durante 54 años. Esta empresa se convirtió en la mayor fábrica nacional de explosivos, teniendo algunos de sus productos adoptados oficialmente por la Armada de Brasil y por la industria de la construcción y la minería en Brasil. De sus investigaciones químicas llegó a la invención del explosivo al que llamó "Rupturita", y patentó e industrializó varios de sus inventos. Fue presidente de la Sociedad Brasileña de Química (1920-1928), vicepresidente (1935-1937) y presidente (19491951) de la Academia Brasileña de Ciencias, fundador y presidente del Centro Brasileño de Investigaciones Físicas (1949-1955) y del Consejo Nacional de Investigaciones (1951-1955). En la Segunda Guerra Mundial desarrolló un proceso para la fabricación de estabilizadores químicos, contralita y acordita, conocimiento que solo los alemanes tenían hasta ese momento.

Su actuación en CEA fue principalmente en el sector de control internacional del uso de energía atómica. La delegación brasileña estuvo integrada por el coronel Orlando Rangel como representante suplente, el profesor Alfredo Pessoa -como asesor-, y Ramiro Saraiva Guerreiro, secretario. Álvaro Alberto fue nombrado presidente de la CEA tanto para 1946 como para 1947. En CEA, Álvaro Alberto buscó proteger la riqueza natural de Brasil, pero buscó cumplir con las órdenes de la Embajada de Brasil de apoyar el Plan Baruch. De hecho, se mostró a favor de este plan, ya que era un consenso que existe la necesidad de crear un organismo internacional para controlar la energía atómica y que este debe estar bajo la tutela del gobierno de Estados Unidos. Sin embargo, Álvaro Alberto, como gran admirador de Estados Unidos, creía principalmente en la posibilidad de cooperación entre los gobiernos brasileño y estadounidense. Estos países deben actuar en el comercio de tecnología nuclear y minerales, así como en la cooperación científica. Es en este contexto que Álvaro Alberto acuñará el principio de compensaciones 
específicas (Andrade, 2010, p. 120). Las compensaciones fueron elaboradas y expuestas en el Informe del 19 de julio de 1947 y preveían:

a) Precio de remuneración, sobre una base necesaria pero no suficiente;

b) Representación permanente en el Organismo Internacional de Control;

c) Cuotas energéticas preferenciales, resultantes de materias primas nacionales;

d) Instalación, en territorio nacional, de reactores primarios ("pilas" de torio o uranio) para producir los denominados "combustibles nucleares" Uranio-233 y plutonio;

e) Instalación, en territorio nacional, de reactores secundarios, destinados a producir energía, a expensas de los "combustibles nucleares”. (Brasil, 1956, p. 2)

La tesis de las compensaciones específicas propugnaba principalmente que la exportación de minerales fisionables se hiciera a partir de la transferencia de tecnología nuclear a los países exportadores. Aunque Álvaro Alberto abogó por los países poseedores de materias primas, no recibió el apoyo de Canadá, el Congo Belga e India, que eran los países con reservas conocidas de uranio y torio. Los representantes de estos países acordaron vender sus minerales, recibiendo solo una compensación económica (Motoyama; García, 1996, p. 64). A partir de las negociaciones que tuvieron lugar en 1946 y 1947 en el CEA de la ONU sobre la implementación del Plan Baruch y el Plan Gromyko, Álvaro Alberto llegó a la siguiente conclusión:

Ante los antagonismos entre la corriente occidental, representada por 14 de los 17 países que ya ejercieron mandato en la CEA, y el bloque ruso, no se ha podido abordar, hasta la fecha, la discusión de todos los reclamos brasileños. El deber de cuidar, por nosotros mismos, de promover el uso de nuestra riqueza, particularmente la atómica, se nos impone con urgencia, con la ayuda, si es necesario, de quienes estén en condiciones de colaborar con nosotros. (Academia Brasileira de Ciências, 1949 Apud Garcia, 1996, p. 66)

Ya en este pasaje, Álvaro Alberto se anticipa un poco al camino que seguiría tras su salida de la ONU CEA. Su búsqueda por lograr el desarrollo científico sería 
su mayor estandarte, como vicepresidente del Centro Brasileño de Investigaciones Físicas (CBPF) y presidente del Consejo Nacional de Investigaciones (CNPq).

En 1947, Álvaro Alberto envió al presidente Dutra un programa para que el desarrollo nuclear en Brasil pudiera iniciarse con más fuerza:

a) nacionalización de todas las minas de material utilizable en energía atómica, especialmente torio y uranio; b) revisión inmediata de estas concesiones mineras, mientras que en Brasil no se practica el ítem a como medida complementaria en el control de las exportaciones, que ahora se realiza bajo tan buenos auspicios; d) ventajas para empresas de renombre de instalar las primeras plantas de tratamiento químico de minerales; e) intensificación inmediata de las actividades científicas, con la creación de centros especializados de cultura e investigación; f) formación urgente de técnicos en grandes centros extranjeros; g) fundación del Consejo Nacional de Investigaciones, para promover y coordinar las actividades científicas y técnicas; h) selección de personal idóneo para su envío inmediato al exterior para mejoras y otras funciones; i) Institución de una Comisión Nacional de Energía Atómica, en la línea del proyecto elaborado y entregado al Ministerio de Relaciones Exteriores; j) prohibición inmediata de traspaso de propiedades de concesiones y minas, hasta que entre en vigencia la nacionalización prevista en el inciso a. (CNPq, 1951) ${ }^{2}$

Todas estas medidas fueron concebidas en el marco de su participación en el CEA de la ONU, y a ellas se sumó la defensa del monopolio del gobierno sobre las actividades en el área de la energía nuclear, que se realiza en régimen de concesión especial. Es posible ver cómo se apoyaron en el trípode del nacionalismo, el monopolio estatal y las compensaciones específicas. Los dos primeros puntos estuvieron vinculados a acciones en territorio brasileño. El tercero estaba relacionado con la conexión entre campo y exterior. Sin embargo, el núcleo de este proyecto fueron las compensaciones específicas, es decir, minerales fisionables a cambio de tecnología nuclear (Motoyama; García, 1996, p. 67).

Más tarde, las compensaciones específicas se convirtieron en un ícono de la lucha de los nacionalistas por la preservación de las reservas nacionales y por la transferencia de tecnología a Brasil. Álvaro Alberto, todavía dentro del CEA, advirtió que la "necesidad de energía atómica para Brasil, más que una cuestión de seguridad, era un tema económico, vital para elevar el nivel de vida de su gente"

\footnotetext{
${ }^{2}$ Ver: Anais do CNPq, 19a Sessão do Conselho Deliberativo, de 09 de julho de 1951.
} 
(Brasil, 1956). La asociación de desarrollo económico y científico fue una de las principales banderas levantadas por el grupo nacionalista.

A su regreso a Brasil, Álvaro Alberto buscó materializar sus propuestas para el desarrollo del binomio Ciencia y Tecnología (CyT). Contaba no solo con su prestigio personal, sino también con un momento único para la ciencia en Brasil. La oportunidad llegó el 12 de abril de 1949, cuando el presidente Dutra nombró una comisión para preparar el borrador para la creación del Consejo Nacional de Investigaciones (CNPq). La comisión encargada de elaborar el borrador tuvo como presidente a Álvaro Alberto. Un mes después, el Congreso recibió un mensaje del presidente proponiendo la creación del $\mathrm{CNPq}$, cuyo proyecto tardaría algún tiempo en ser aprobado por el Congreso. La energía nuclear ocupó un lugar destacado en el mensaje presidencial.

Al final del gobierno de Dutra, la Ley $N^{\circ}$ 1310, el 15 de enero de 1951, crea el CNPq. Álvaro Alberto no había podido crear una Comisión de Energía Atómica, lo que significó que el CNPq terminó acumulando las dos funciones, es decir, impulsar el desarrollo científico en todas las áreas, y ser responsable de la política nuclear brasileña. El artículo 5 lo estipula de la siguiente manera:

Todas las actividades relacionadas con el uso de la energía atómica estarán bajo el control del Estado, a través del CNPq, o cuando sea necesario, del Estado Mayor de las Fuerzas Armadas, u otro organismo que designe el Presidente de la República, sin perjuicio de las investigaciones científicas y tecnológicas. (Brasil, 1951 Apud Motoyama; Garcia, 1996, p. 75)

Álvaro Alberto aún logró cubrir otros puntos. El CNPq se comprometió a fomentar la investigación y la prospección de reservas materiales aptas para el uso de la energía nuclear. Obtuvo una prohibición sobre la exportación de torio y uranio, excepto de gobierno a gobierno. El almirante Álvaro Alberto fue designado presidente del CNPq y buscó, durante todo el tiempo que estuvo al frente de este organismo, implementar la tesis de compensaciones específicas.

Sin embargo, se ha logrado poco con la política de negociación. Debido a la dificultad de lograr ganancias reales con Estados Unidos, el Almirante buscó un consorcio europeo para comprar ultracentrífugas que pudieran dar a Brasil autonomía para procesar nuestros minerales en combustible nuclear. A pesar de estar listo para embarcarse, Estados Unidos descubrió la negociación e invocó el tratado de paz con Alemania, ya que esta formaba parte de este consorcio y no podía transferir tecnologías sensibles sin la autorización de las naciones ganadoras. Así, las 
ultracentrífugas no pudieron desembarcar y, tras un escándalo por la compra y montaje de un sincrociclotrón para la CBPF, el almirante fue destituido del CNPq en 1955.

\section{Ministerio de Relaciones Exteriores}

El nombramiento de Álvaro Alberto a la presidencia del CNPq haría que este organismo adopte una política nacionalista, especialmente en lo que respecta a los materiales estratégicos. La posición del CNPq entró en conflicto directo con la orientación de Itamaraty. El titular del Ministerio de Relaciones Exteriores era João Neves da Fontoura, quien asumió el cargo por segunda vez, ya que, durante el gobierno de Dutra, había ocupado esta cartera durante algunos meses.

En su segundo gobierno, Getúlio Vargas buscó asegurar la conciliación de diferentes intereses. Los nombramientos hechos por Vargas dependieron de varios factores: "Indicaciones personales de Vargas y João Neves da Fontoura, presión de Adhemar de Barros, gobernador de São Paulo, e interés de grupos militares” (Carone, 1985, p. 42), y el primer nombre por confirmar fue João Neves. Además de ser el coordinador de la campaña de Getúlio, Estados Unidos buscó saber quién sería el representante brasileño en la IV Conferencia de Cancilleres Americanos. Para los demás ministerios, Vargas eligió varios elementos vinculados al Partido Socialdemócrata (PSD) para su composición.

El PSD fue el partido mayoritario en el período 1945-64 y su génesis está asociada al aparato administrativo del Estado Novo y, principalmente, a los interventores designados por Vargas. Durante este período tuvo el mayor número de victorias en las elecciones. Su programa para el área de política económica y financiera proponía que el Estado estimule la iniciativa privada, supervise la explotación de recursos minerales y naturales, organice industrias básicas -con énfasis en acero, petróleo y combustibles en general-, evite la formación de fideicomisos, cárteles o monopolios que pudieran comprometer la producción y perjudicar al consumidor, y también defendió la constitución de un Banco Central para que se modernizara y regulara el sistema bancario nacional. La inflación fue identificada como el problema más grave a abordar y, al respecto, el PSD señaló que era necesario equilibrar el presupuesto, disciplinar la expansión del crédito y mantener las emisiones bajo control. Se debe admitir la entrada de capital extranjero a la economía nacional, ya que beneficiaría el desarrollo del país. Sin embargo, era necesario que este capital fuera regulado y dirigido a los sectores más convenientes. En cuanto a las remesas de utilidades al exterior, se propuso que se sometiera a un control más estricto, provocando que la mayor parte de las utilidades se retengan en el país. Su percepción de la política internacional era que el país debía ser solidario 
con las demandas del continente, es decir, brindar su solidaridad continental, respetar el arbitraje internacional cuando había temas contenciosos y, en general, repudiar la guerra de conquista.

La Unión Nacional Democrática (UDN) aparece como el segundo partido más grande de ese período, y tiene sus orígenes en el Manifiesto Mineiros de octubre de 1943, democratización de las instituciones políticas brasileñas. Tenía una plataforma liberal, representada principalmente por el liberalismo burgués; estaba a favor de la entrada de capitales extranjeros al enfatizar la necesidad de estar permanentemente alerta contra el abuso del poder estatal; afirmó que el Banco do Brasil debe tener autonomía y que es necesario reducir los gastos improductivos y controlar la emisión de papel moneda. Su principal posición respecto a la industrialización es que debe ser responsabilidad del Estado o de las empresas que cuentan con su orientación y participación en áreas estratégicas.

El Partido Laborista Brasileño (PTB) fue el tercer partido más grande y, además, representó al partido que más creció durante este período. El PTB se organizó desde la máquina del Estado Novo, pero principalmente desde la estructura sindical corporativa de la década de 1930 (Schmitt, 2005, pp. 11-18). Su primer programa, lanzado el 14 de septiembre de 1945, pretendía un gran espacio para la defensa de los derechos laborales para que la economía pudiera ser planificada por el Estado a través de su orientación, intervención y gestión, con el objetivo de servir a todos los sectores y, principalmente, que la producción del país pudo satisfacer las necesidades internas. En cuanto a las ganancias de las empresas privadas, reconoció que debe haber un límite para que haya una mejor distribución de la riqueza. Su orientación nacionalista y la crítica al alineamiento con Estados Unidos hicieron de este partido uno de los más silenciosos en lo que respecta al Acuerdo de Asistencia Militar en el Congreso Nacional. Después de todo, el partido no haría bien en ir en contra de un acuerdo firmado por el presidente.

En general, estos tres partidos se movieron de la siguiente manera a través de las categorías definidas anteriormente:

El espectro se extendió desde la UDN, cuya mayoría de miembros se identificó con el neoliberalismo, pasando por el PSD, cuyos líderes urbanos apoyaron en gran medida el nacionalismo desarrollista, pasando por el PTB, más sólidamente a favor del nacionalismo desarrollista, hasta que finalmente llegó el ala izquierda del PTB y el Partido Comunista Brasileño (ilegal desde 1947, pero todavía activo en política), que abrazó el nacionalismo radical. (Skidmore, 2010, p. 125) 
De la actuación de Horácio Lafer al frente del Ministerio de Hacienda, en el segundo gobierno de Vargas, y de João Neves, se desprende que la posición de los representantes del PSD en el poder, con respecto a la política exterior brasileña, fue una de alineación con los Estados Unidos. Esta postura osciló entre la definición de desarrollismo nacionalista y no nacionalista.

Vargas también invitó a João Cleofas, de la UDN de Pernambuco, a ocupar el Ministerio de Agricultura. El presidente terminó optando por nombramientos que hicieron que su ministerio fuera predominantemente conservador. Sin embargo, para el cargo de ministro de Guerra llamó al general Newton Estillac Leal, presidente del Clube Militar y vinculado a la corriente nacionalista dentro del Ejército. Este ministerio de Vargas pasó a conocerse como el "ministerio de la experiencia”, es decir, si no se cumplían sus objetivos, podía ser reemplazado, como de hecho se hizo. Una vez más Vargas intentaría ser "el árbitro ante las distintas fuerzas sociales y políticas” (Fausto, 2009, p. 224). Para ello cuenta con el apoyo de João Neves da Fontoura.

En 1950, poco después del resultado de las elecciones que eligieron a Vargas, Fontoura fue elegido ministro de Relaciones Exteriores. Asumió el cargo el 1 de febrero de 1951, y permaneció hasta el 19 de junio de 1953. Su orientación proestadounidense, como presidente de Ultragás, una concesionaria de Standard Oil en Brasil, le hizo creer que era posible atraer nuevamente el interés estadounidense a la región. "En el período 1951-1952, cuando un fugaz pero patente interés norteamericano resurgió en toda la zona y, especialmente, en Brasil, Fontoura notó de inmediato las oportunidades que se abrían al país y se preparó para explorarlas” (Alves, 2007, p. 150).

En este sentido, cabe destacar su compromiso con la cooperación económica y militar con Estados Unidos, que se evidenció en su apoyo al envío de tropas brasileñas a la Guerra de Corea. La dirección de política exterior del canciller fue similar a la de Raúl Fernandes, sin embargo esta similitud se restringió a los aspectos centrales de la Guerra Fría y la aproximación con Estados Unidos. La mayor diferencia entre el gobierno anterior y el de Vargas fue la exigencia de este último de que debe haber reciprocidad económica en las relaciones con el gobierno de Estados Unidos. La reciprocidad económica se tradujo en apoyo a la industrialización brasileña, como se había hecho cuando Vargas ocupó la presidencia por primera vez (Barreto, 2001, p. 189).

João Neves creía en el alineamiento con Estados Unidos, estaba a favor del ingreso de recursos extranjeros en áreas consideradas estratégicas para los nacionalistas, siendo esta la orientación que entró en conflicto con los defensores de una política nacionalista en el tema de minerales estratégicos. . La posición que 
tomó fue alinearse con el gobierno de Estados Unidos por razones ideológicas, pero esta alineación constituyó no solo un objetivo, sino también un instrumento de la política exterior brasileña. A cambio, se esperaba que Brasil recibiera asistencia económica y militar. Este fue un intento de reeditar la alineación "negociada" que Vargas y Oswaldo Aranha implementaron durante la Segunda Guerra Mundial.

El ministro percibió la Guerra de Corea como una situación favorable para las negociaciones entre Brasil y Estados Unidos y, para él, el poder de negociación brasileño en relación con Washington era muy prometedor. Sin duda, esta fue una visión muy optimista y positiva de la realidad. João Neves advirtió que es necesario establecer una asociación estrecha entre los reclamos brasileños y la necesidad de que Estados Unidos obtenga apoyo latinoamericano para su acción en el conflicto asiático. En su opinión, el apoyo brasileño a las prioridades político-estratégicas de Washington tendría el efecto de ampliar las posibles ganancias en el ámbito de las relaciones bilaterales entre los dos países (Silva, 1995).

A pesar de todo el apoyo brindado por João Neves y por el Ministerio de Relaciones Exteriores al envío de soldados brasileños al conflicto asiático, "sabemos, en todo caso, que el Ministerio de Relaciones Exteriores y su representante no tuvieron más que un fuerte papel asesor. En cuanto a organización, el Ejército era, sin duda, el más importante” (Alves, 2007, p. 154). En este sentido, este Ministerio fue el encargado de redactar una nota que entregaría el general Goes Monteiro al embajador de Estados Unidos, en agosto de 1951.

En esta nota, João Neves,

afirmó que el General debe contactar a los jefes militares de la ONU 'para planificar y para que João Neves lleve a cabo la preparación indispensable para la colaboración efectiva de Brasil'. Esta nota, sin embargo, no fue entregada, siendo reemplazado, por orden de Vargas. (Alves, 2007, pág. 153)

Así, el presidente asumió su papel de líder, "vetando las respuestas del Itamaraty al tema, que consideró excesivamente comprometedoras" (Alves, 2007, p. 153). La misión del general Goes Monteiro a los Estados Unidos resultó ser un intento de ganar tiempo, "como resume Lourival Fontes, [el general Goes] fue a los Estados Unidos principalmente para hacer trampa". (Alves, 2007, pág. 153).

Al regreso de su misión, el general Goes trajo consigo la propuesta de un convenio de asistencia militar en la línea de lo que habían firmado Vargas y Roosevelt en 1942. La firma del convenio militar, el 15 de marzo de 1952, fue recibida con grandes críticas, e incluso incitó más el conflicto entre diferentes 
corrientes políticas, dentro de la sociedad y las fuerzas armadas. En cuanto al envío de tropas a la Guerra de Corea, la tramitación del Acuerdo Militar en el Congreso, que, dicho sea de paso, fue aprobado con gran dificultad, fue un punto decisivo para que este tema también fuera ampliamente discutido, junto con el tema del suministro de arenas de uranio y monacita para los Estados Unidos. De hecho, la Guerra de Corea -finalizada en los primeros meses de 1953-, fue dejando paulatinamente un tema en la agenda de las relaciones entre los dos países.

Para João Neves, las relaciones de Brasil con América Latina estaban destinadas a asegurar una posición destacada para el país. En este contexto, Argentina fue el principal rival de Brasil. Las relaciones entre Brasil, Argentina y Estados Unidos se orientaron a mantener un equilibrio de poder.

La relación entre Brasil y Argentina será uno de los temas más delicados para João Neves.

Su firme oposición a los supuestos intentos de Vargas y Perón de reeditar el Pacto $\mathrm{ABC}$, ahora con motivaciones económicas, se vinculó, en primer lugar, a una visión extremadamente negativa del peronismo y las posibles asociaciones que podría establecer con el trabajo brasileño en la implementación de una supuesta "república sindicalista". (Alves, 2007, p. 109)

Las denuncias hechas por João Neves, luego de su destitución del gobierno, sobre los entendimientos entre Vargas y Perón para firmar un pacto entre Argentina, Brasil y Chile, tenían que ver con su adhesión a grupos anti-getulistas. Tales denuncias encajan en el contexto más amplio del proceso de desestabilización del gobierno de Vargas y la creciente polarización entre la oposición liberalconservadora y las fuerzas nacionalistas de centro izquierda. Al mismo tiempo, el peronismo, según el ministro, tenía el objetivo de formar un bloque continental bajo el liderazgo argentino para contrarrestar el poder estadounidense. Un posible acercamiento entre Argentina, Brasil y Chile fue temible, ya que podría afectar el corazón del sistema interamericano. Los bloques regionales fueron vistos con repudio por João Neves, ya que podrían abrir brechas peligrosas que hicieron posible la exclusión de Estados Unidos. En ese sentido, buscó estrechar lazos con Estados Unidos, pues consideró que la cooperación económica, política y militar del sistema interamericano ya estaba asegurada por el TIAR y la OEA.

En este período, luego de su salida del Ministerio de Relaciones Exteriores en junio de 1953, se hizo más latente su aversión a la izquierda y a los movimientos de movilización de masas como base de apoyo al gobierno. Su salida marcó un 
resurgimiento de sus posiciones conservadoras, lo que lo llevó a convertirse en adversario de Vargas.

La crisis de 1953 y 1954 llevó a Vargas a realizar algunos cambios en la composición de sus ministerios. Entre estos cambios, los más relevantes fueron el reemplazo del Ministro de Relaciones Exteriores, Finanzas y Trabajo, y así fueron nombrados Vicente Rao, Oswaldo Aranha y João Goulart, respectivamente. El nombramiento de Rao para el Ministerio de Relaciones Exteriores puede explicarse por sus antecedentes. Abogado paulista vinculado a la UDN, encabezó la misión brasileña ante la ONU en 1950 y fue ministro de Justicia de 1934 a 1937.

[...] simultáneamente representaba a un hombre más leal al presidente de lo que lo había sido João Neves da Fontoura y, al mismo tiempo, provenía de un partido de oposición. Sin embargo, lo más probable es que Vargas vio en Rao a un hombre de expresión media y que no se atrevía a actuar independientemente de la administración a la que pertenecía. (Vizentini, 2008, p. 96-97)

El 1 de julio de 1953, Rao asumió el cargo de Ministro de Relaciones Exteriores. Su gestión estuvo marcada por abordar los temas interamericanos, pero principalmente por la búsqueda del reconocimiento de la OEA como una organización que tenía la tarea de resolver los conflictos que surgían en América Latina, y cómo se debían resolver los problemas continentales. La situación que enfrentó Rao incluyó el cambio de actitud de Estados Unidos.

En julio de 1953, el ministro de Relaciones Exteriores, Oswaldo Aranha y Getúlio Vargas se reunieron con Milton Eisenhower, hermano del presidente de Estados Unidos. En esta reunión, Milton Eisenhower informó que el gobierno de Estados Unidos no otorgaría un trato preferencial a Brasil, se restringiría el otorgamiento de préstamos y se deberían resolver los problemas con el Banco Mundial (Barreto, 2001, p. 200). Estas recomendaciones vinieron contra el final de la Comisión Mixta.

La administración de Eisenhower (1953-1961) no tenía interés en los proyectos de desarrollo económico: "la falta de voluntad del gobierno de los Estados Unidos de comprometer fondos del BIRF y del Eximbank para proyectos de desarrollo en Brasil terminó conduciendo a la desarticulación de la Comisión Conjunta en diciembre de 1953” (Hirst, 2011, pág.27). El informe final de la Comisión, ampliamente difundido en 1954, destacó la necesidad de expandir el capital extranjero en la economía brasileña. 
Para el gobierno de Estados Unidos, la participación del capital privado en la economía brasileña era relevante, por lo que era imperativo que Brasil creara las condiciones para atraer capital extranjero. Así, el nuevo gobierno de Estados Unidos demostró claramente que no estaba dispuesto a asumir los compromisos asumidos por la política económica de Truman (Skidmore, 2010, págs. 152-153).

Durante el gobierno de Rao, Brasil buscaría ampliar las posibilidades de instituir una política nuclear, para lo cual el almirante Álvaro Alberto viajaría a Alemania en busca de acuerdos que viabilizaran la compra de reactores para investigación en energía nuclear. La ocasión resultó ser oportuna ya que la Comisión Mixta de Desarrollo Económico Brasil-Alemania fue instituida el 4 de septiembre de 1953. Ese mismo día, Vargas sancionó la Ley 2004 para la creación de Petrobras. La reacción estadounidense a este último evento se produjo mediante la cancelación del 2o Acuerdo Atómico. Este acto dejó a Orquima, la empresa encargada del abastecimiento de la monacita, en dificultades económicas. Para reparar el daño causado por la cancelación de ese acuerdo, Estados Unidos propuso que se hiciera un ajuste para cambiar la monacita por trigo. Este acuerdo fue conocido como el Acuerdo del Trigo, o el Acuerdo del Trigo x Torio, siendo firmado el 20 de agosto de 1954.

Con el suicidio de Vargas, Café Filho asumió la presidencia y Raúl Fernandes fue nombrado canciller. Raúl Fernandes permanecería al frente del MRE hasta el 12 de noviembre de 1955, es decir, hasta poco antes del inicio de las negociaciones para la firma del IV Acuerdo Atómico. Cuando se firmó este último acuerdo, José Carlos de Macedo Soares ya ocupaba el cargo de ministro de Asuntos Exteriores. En general, el MRE no tuvo una orientación facilitadora para la obtención de tecnología para promover la política nuclear brasileña. En cuanto a la política estratégica de exportación de minerales, el MRE demostró estar al servicio de las demandas de Washington, es decir, la exportación irrestricta de estos minerales aliada a la imposición de dificultades en la implantación de una industria nuclear nacional.

\section{El Segundo Acuerdo Atómico}

Este segundo acuerdo marca la consagración del modelo exportador no nacionalista de minerales estratégicos brasileños. El acuerdo firmado el 21 de febrero de 1952 fue la primera ocasión en que el MRE y el recién creado CNPq discreparon sobre la política de exportación de minerales. Las dos instituciones estaban a favor de la exportación de minerales, el desacuerdo radicaba en la forma en que debía hacerse. 
El 2 Acuerdo Atómico fue el resultado de un largo período de negociaciones entre Brasil y Estados Unidos. João Neves había sido investigado por el gobierno de Estados Unidos desde diciembre de 1950. En su libro "Testimonios de un exministro", afirma que:

\begin{abstract}
Antes de mi viaje a Washington, el gobierno de Estados Unidos había estado buscando, junto con el nuestro, la venta de grandes cantidades de monacita, como contribución al trabajo de seguridad mutua. El tema fue arrastrado de un lado a otro al Consejo de Seguridad Nacional y discusiones de los órganos competentes. El Embajador de los Estados Unidos, Herschell Johnson, una destacada personalidad en su carrera diplomática, consciente de nuestras realidades y que había hecho buenos amigos aquí en todos los círculos, fue en persona a conversar con el presidente Vargas y le formuló el deseo de Truman de que solicitara se cumpliera la venta de monacita. Mientras se esperaba la decisión presidencial, los técnicos de los dos altos partidos discutieron, dentro y fuera de Itamaraty, detalles sobre el posible ajuste, las condiciones para el mismo y su ejecución, eventualmente reduciendo las cantidades propuestas por Washington. (Fontoura, 1957, págs. 104-105)
\end{abstract}

La percepción del tema de la exportación de minerales estratégicos a los ojos de João Neves estaba ligada a contribuir a la defensa mutua. La reducción de las cantidades inicialmente solicitadas por Estados Unidos se percibe como una señal de protección de los intereses brasileños. Según el ministro, en una consulta realizada por Gordon Dean, presidente de la Comisión de Energía Atómica de Estados Unidos, João Neves "expresó el deseo de Estados Unidos, de comprar todo el uranio que no necesitábamos”. (Consejo de Seguridad Nacional, 1951) El 14 de diciembre de 1951, Gordon Dean presentó el proyecto del convenio que se iba a firmar entre Brasil y Estados Unidos para la investigación y exploración de minerales de uranio brasileños. En esta primera propuesta se afirmó que:

En vista de los objetivos de defensa comunes de los dos gobiernos, el Gobierno brasileño se compromete a vender al Gobierno de los Estados Unidos de América el mineral de uranio extraído que excede las necesidades de los programas de energía atómica. De acuerdo con este principio, las cantidades especificadas que serán compradas por el Gobierno de los Estados Unidos de América, y los precios relacionados serán fijados de común acuerdo de vez en cuando entre los dos 
gobiernos. Los excedentes de minerales de uranio del Gobierno de los Estados Unidos de América que declaren no ser requeridos por su programa de energía atómica pueden ser dispuestos libremente por el Gobierno brasileño de manera compatible con los objetivos comunes de defensa. (Consejo de Seguridad Nacional, 1951, p. 64)

João Neves se mostró favorable a las exportaciones a través de algunos cambios en el texto del acuerdo, pero en general aprobó la exportación de minerales estratégicos. Para los desarrollistas nacionalistas del sector público, los términos del acuerdo faltaron el respeto a la tesis de compensaciones específicas. Ahora, era necesario que Estados Unidos ofreciera transferencia de tecnología y apoyo al programa brasileño de energía atómica. En el pasaje mencionado anteriormente, el gobierno de EE.UU. solo está dispuesto a pagar el precio ajustado por los minerales. Para los desarrolladores del sector público "no nacionalistas", la negociación de minerales estratégicos con Estados Unidos fue la oportunidad que se presentó para contrarrestar los reclamos estadounidenses. Este es un punto que João Neves explorará durante la 17a Sesión del Consejo de Seguridad Nacional. Para él, desde el momento en que Brasil se negó a enviar tropas a la Guerra de Corea, fue necesario contribuir de alguna manera al esfuerzo bélico norteamericano, aunque fuera una contribución indirecta.

Lograr un consenso sobre la exportación de minerales estratégicos no fue una tarea fácil, pero en la Sesión del 22 de diciembre de 1951, el Consejo de Seguridad Nacional finalizó de la siguiente manera:

Como ningún otro miembro del Consejo quiso hacer uso de la palabra, el PRESIDENTE declaró cerrados los debates y propuso la siguiente pregunta preliminar: si Brasil debería entablar negociaciones con el gobierno estadounidense para la venta de minerales atómicos. Todos los integrantes del Consejo de Seguridad Nacional se manifiestan de acuerdo con esta propuesta y sugiere el PRESIDENTE, por lo que el Ministerio de Relaciones Exteriores es el encargado de orientar y conducir las negociaciones, siendo aprobada por unanimidad la sugerencia. (Consejo de Seguridad Nacional, 1951, p. 68)

El borrador final del Acta de esta sesión del Consejo de Seguridad Nacional otorgó al Ministro de Relaciones Exteriores la libertad de abordar el tema de las exportaciones de minerales estratégicos. Y, de hecho, eso fue lo que hizo, porque dos meses después de esta sesión se firmó el Acuerdo. A partir de entonces, surgió 
una disputa entre el CNPq y el MRE, y este último con el CSN. De hecho, al final de la sesión del CSN, los miembros allí presentes, incluido el ministro Estillac Leal, permitieron que las negociaciones avanzaran, pero aun así, fue necesario que João Neves volviera al Consejo para presentar los términos del acuerdo. Sin embargo, el mayor obstáculo fue la Ley 1310, que consideró la participación del CNPq en las negociaciones para la exportación de minerales estratégicos. La orientación nacionalista del CNPq generó un problema para la aprobación del Acuerdo. La solución encontrada por João Neves fue la creación de la Comisión Estratégica de Exportación de Materiales (CEME), que administraría estas exportaciones.

\section{El Acuerdo del Trigo}

El 3er Acuerdo Atómico se conoció como el Acuerdo del Trigo, ya que sus términos estipulaban que el trigo estadounidense se cambiaría por torio brasileño. El Acuerdo del 20 de agosto de 1954, firmado apenas cuatro días antes del suicidio de Vargas, refleja la consolidación del modelo exportador de minerales estratégicos brasileños. Entre la firma del $2^{\circ}$ Acuerdo y el $3^{\circ}$ Acuerdo Atómico, la situación política nacional sufrió fuertes cambios.

Como hemos visto, el $2^{\circ}$ Acuerdo preveía el suministro de monacita, sales de cerio y tierras raras por un período de tres años. Si bien este acuerdo preveía el suministro de minerales por tres años, Estados Unidos indicó que quería adquirir toda la cantidad de minerales prevista para los tres años de una sola vez. Brasil cumplió con prontitud con la solicitud de Estados Unidos, sin embargo, la única compensación obtenida, que fue la compra de los subproductos de estos minerales, no fue cumplida (Andrade, 2010, p. 135).

La restricción a las remesas de utilidades, la exploración de petróleo y su monopolio estatal con la creación de Petrobras, y la creación de una empresa estatal para el suministro de energía eléctrica en abril de 1954, Eletrobras, crearon una situación delicada para la permanencia de Vargas en el poder. En este sentido, Vargas buscó calmar a los sectores más conservadores de las Fuerzas Armadas, con el nombramiento del general Zenobio da Costa al Ministerio de la Guerra. Zenobio se presentó como un hombre de confianza de Getúlio y un gran combatiente del comunismo. Sin embargo, al adoptar una línea más nacionalista en el área económica y responsabilizar al capital extranjero por problemas en la balanza de pagos, el presidente se distanció no solo de los sectores sociales conservadores, sino también del gobierno de Washington.

En este contexto, el primer Acuerdo Torio x Trigo, que contó con el apoyo del ministro de Hacienda, Oswaldo Aranha, quien argumentó que la operación era importante, ya que una parte también se pagaría en dólares y esto era una especie de 
contraprestación para la exportación de minerales estratégicos e importaciones de trigo. En el planteamiento de Motivos Reservados del No 1139, Aranha argumenta con el Presidente que: "Luego de haber examinado la propuesta estadounidense, la referida Comisión la aprobó, ya que podría ser considerada, respecto de los suministros a realizar por Brasil, como ejecución simple de los citados contratos de 21 de febrero de 1952" (Exposición de Motivos Reservados No 1139. Apud, Guilherme, 1958, p. 148-149).

El 3er Acuerdo Atómico entra en este contexto como un intento de actuar en el doble sentido de favorecer al gobierno de Estados Unidos, ya que resolvió el problema de los excedentes agrícolas y garantizó que "la materia prima sea almacenada como reserva estratégica, ya que el torio es necesario para la funcionamiento de reactores superregenerativos " (Exposición de motivos reservados No 1139, Apud, Guilherme, 1958, p.149).

El intercambio de trigo por torio expuso el carácter comercial de la operación que ayudó al Departamento de Agricultura de Estados Unidos a continuar su programa de subsidios a los agricultores estadounidenses. La firma también contemplaba un último intento de Vargas por pacificar las relaciones con el gobierno de Estados Unidos, que se deterioraban, especialmente tras la orientación nacionalista de la política nacional en petróleo, electricidad y ganancias de empresas extranjeras.

El Cuarto Acuerdo Atómico se firmó en base a una solicitud del Departamento de Estado de EE.UU., que ofrecía un nuevo ajuste. En esta transacción, Estados Unidos compraría 300 toneladas de óxido de torio, en productos industrializados. Este Acuerdo fue firmado y posteriormente aprobado por el presidente Juscelino Kubitschek, comprometiendo una vez más a Brasil a exportar minerales a Estados Unidos, sin que se considere una compensación específica en el cálculo de las negociaciones.

La firma del III y IV Acuerdo Atómico, al mismo tiempo que marca la consolidación de una forma de exportar materiales estratégicos, abre también al país a negociaciones con Estados Unidos para la transferencia de tecnología nuclear, considerada por los críticos como obsoleta. Bajo el gobierno del presidente Café Filho, la situación nacional fue asumida por el internacionalismo, traducido en alineación con Estados Unidos, anti obrero y militarista. El nuevo presidente permaneció en el poder durante 17 meses y su gobierno encontró su principal base de apoyo en el ejército de la Escuela Superior de Guerra (ESG). Entre los nombramientos realizados por Café Filho se destaca el general Juárez Távora al frente de la Casa Militar. Junto a Távora, el mandatario logró firmar algunos 
acuerdos y alianzas que aseguraron no solo el apoyo de su gobierno, sino también la dirección del sector nuclear para la cooperación con Estados Unidos.

\section{Consideraciones finales}

La firma de los Acuerdos Atómicos revela cómo la articulación de factores coyunturales y estructurales influyó en el proceso que condujo a su firma. Los términos bajo los cuales se firmaron estos acuerdos también revelan la interacción de fuerzas que tuvo lugar a nivel nacional. Por un lado, grupos vinculados al sector industrial, la diplomacia brasileña $y$, por otro, grupos vinculados al ejército nacionalista, el CNPq y el Consejo de Seguridad Nacional, disputaron la implementación de un proyecto de desarrollo. Los primeros tuvieron éxito porque lograron llevar sus condiciones a la mesa de negociaciones. El segundo grupo, a pesar de no poder realizar muchos de sus reclamos en el campo de los minerales estratégicos, y lejos de formular la política de exportación de estos materiales, este grupo fue el encargado de implementar el proyecto de desarrollo nuclear brasileño.

Considerando que los Acuerdos Atómicos son el resultado de negociaciones en las que los tomadores de decisiones buscaron maximizar sus ganancias, principalmente en el escenario político interno, sería posible delinear los principales temas que movieron a estos actores. Estos tomadores de decisiones también buscaron lograr de alguna manera algunas concesiones externas, es decir, el proceso de toma de decisiones que condujo a la exportación de materiales estratégicos a Estados Unidos aseguró el fortalecimiento e intensificación de las dos principales corrientes de pensamiento económico y político que disputaban la situación del escenario político nacional.

La creación, en 1947, de la Comisión de Estudios y Supervisión de Materiales Estratégicos y, posteriormente, en 1951, del Consejo Nacional de Investigaciones, y la legislación que regulaba la investigación y minería de materiales que tuvieran relación directa con la producción de energía nuclear, mediante el Decreto $\mathrm{N}^{\circ}$ 30.230 del 31 de diciembre de 1951, constituyeron la base legal e institucional de un proyecto nacionalista que permitiría al país desarrollar la producción de energía nuclear. La legislación fue fuertemente proteccionista con respecto a la explotación de estos recursos. A pesar de la legislación creada para proteger los recursos minerales del suelo brasileño, el Ejecutivo en diferentes momentos dio su consentimiento para la firma de acuerdos que negociaron la exportación de materiales estratégicos.

En lo que respecta a la energía nuclear y la exportación de materiales estratégicos, el grupo principal que se formó en torno al apoyo a este proyecto de desarrollo nacionalista lo formaron sectores nacionalistas vinculados 
principalmente al Estado Mayor de las Fuerzas Armadas, al Consejo Nacional de Investigaciones y a la Consejo de Seguridad Nacional. Para este grupo, se había llegado a un consenso en torno a la tesis de compensaciones específicas. Por otro lado, la posición a favor de un proyecto pro-estadounidense se identifica con el grupo vinculado al Ministerio de Relaciones Exteriores y la Comisión Estratégica de Exportación de Materiales.

En este contexto, los actores que ganaron más protagonismo en el proceso y, así, lograron firmar los Acuerdos entre Brasil y Estados Unidos, fueron vinculados a corrientes de desarrollo nacionalistas y no nacionalistas. Evitamos el uso de denominaciones nacionalistas y liberales o internacionalistas, de uso común en la época, ya que nos dimos cuenta de que dificultarían la comprensión de las distintas tonalidades, que configuraban las posiciones adoptadas por los distintos grupos que tenían un mayor compromiso con el tema nuclear.

A partir del análisis del contexto interno, podemos ver los fuertes vínculos que se establecen entre las expectativas que tanto los gobiernos de Estados Unidos como los de Brasil alimentaron entre sí. En este contexto, los Acuerdos Atómicos fueron utilizados y justificados para garantizar la continuidad del proyecto de desarrollo brasileño y, al mismo tiempo, el monopolio de las exportaciones a Estados Unidos. Frente a un sistema político inestable, en el que las fuerzas sociales dominantes establecieron alianzas de corto plazo, el tema de la exportación de materiales estratégicos se presentó como un problema para los tomadores de decisiones brasileños, divididos y representados por corrientes nacionalistas y no nacionalistas, al mismo tiempo que apareció como una solución a los problemas generados por la relación Brasil-Estados Unidos.

La inestabilidad interna de los gobiernos de Dutra y Vargas y, sobre todo, los vínculos establecidos entre miembros de los gobiernos de Estados Unidos y Brasil, sellaron la firma de dichos acuerdos. Los materiales estratégicos entraron como moneda de cambio, en un juego en el que ciertos grupos favorecían el capital extranjero y, así, favorecían la venta de estos minerales, sin compensación específica, con miras a su fortalecimiento interno. Los principales actores que compartieron esta visión y estuvieron involucrados en la firma de estos acuerdos fueron los ministros João Neves da Fontoura, Oswaldo Aranha y Raúl Fernandes. En la línea opuesta a ésta, estaba el almirante Álvaro Alberto.

\section{Referencias}

Andrade, A. (2010) Acordos e Desavenças na Política Nuclear. In: Neto, M. O Militar e a Ciência no Brasil. Rio de Janeiro: Gramma. 
Altemani, H.; Lessa, A. C. (2006). Politica Internacional Contemporânea: mundo em transformação. São Paulo: Ed. Saraiva.

Altemani, H. (2005). Política Externa Brasileira. São Paulo, Saraiva.

Alves, V. C. (2007). Da Itália à Coreia: decisões sobre ir ou não à guerra. Belo Horizonte: Editora UFMG; Rio de Janeiro: IUPERJ.

Barreto, F. (2001). Os sucessores do Barão: Relações Exteriores do Brasil 1912-1964. São Paulo: Paz e Terra.

Bielschowsky, R. (2000). Pensamento econômico brasileiro: o ciclo ideológico do desenvolvimentismo. $5^{\mathrm{a}}$ ed. Rio de Janeiro: Contraponto.

Conselho Nacional de Pesquisas (1951). Anais do CNPq, 19a Sessão do Conselho Deliberativo, de 09 de julho de 1951.

Conselho de Segurança Nacional. Ata da 17a Sessão do Conselho Nacional de Segurança. Documento localizado no Arquivo Nacional.

Brasil. (1956). Relatório n. ${ }^{o}$ 771, 25/11/1953. Comissão Parlamentar de Inquérito: Problema da Energia Atômica. Brasília: Câmara dos Deputados.

Carone, E. (1985). A República Liberal: II Evolução politica (1945-1964). São Paulo: DIFEL.

Cervo, A. (2008). Inserção Internacional: formação dos conceitos brasileiros. São Paulo: Ed. Saraiva.

Dhenin, M. (2010). O papel das Forças Armadas no planejamento e na implantação da matriz energética brasileira: Os casos do petróleo e da energia nuclear. Dissertação de Mestrado. Programa de Pós-Graduação em Estudos Estratégicos, Universidade Federal Fluminense. Niterói.

Fausto, B. (2009). História concisa do Brasil. 2a Ed. São Paulo: Edusp.

Fontoura, João Neves. (1957). Depoimentos de um ex-ministro (Peronismo - Minerais Atômicos - Poltica Externa. Rio de Janeiro: Organização Simões.

Garcia, J. (2000). Álvaro Alberto: A ciência do Brasil. Rio de Janeiro: Contraponto; PETROBRAS.

Guilherme, O (1957). O Brasil e a Era Atômica. Rio de Janeiro: Ed. Vitória.

HIRST, M. (2011) As relações Brasil - Estados Unidos desde uma perspectiva multidimensional: evolução contemporânea, complexidades atuais e perspectivas para o século XXI. Tese de doutorado, Programa de Pós-Graduação em Estudos Estratégicos Internacionais, Universidade Federal do Rio Grande do Sul. Porto Alegre.

Mendonça, S. R. (1986). Estado e Economia no Brasil: opções de desenvolvimento. $3^{\text {a }}$ ed. Rio de Janeiro: Ed. Graal.

Milza, P. (2003). Política interna e política externa. In: RÉMOND, René. Por uma história política. 2a Edição. Rio de Janeiro: FGV. 
Motoyama, S.; Garcia, J. (1996). O Almirante e o novo Prometeu: Álvaro Alberto e a CETT. São Paulo: UNESP.

Putnam, R. D. (2010). Diplomacia e política doméstica: a lógica dos jogos de dois níveis. Revista de Sociologia e Política,18(36), 147-174. Disponível em: https://dx.doi.org/10.1590/S0104-44782010000200010

Santos, T. L. (2009). Nos bastidores da criação da Comissão Nacional de Energia Nuclear: disputas políticas e interesses econômicos. Dissertação de Mestrado. Rio de Janeiro: UERJ.

Salles, D. (1958) As razões do nacionalismo. São Paulo: Fulgor.

Silva, A. M. (1995). O Brasil no continente e no mundo: atores e imagens da política externa brasileira contemporânea. Estudos Históricos, v.8, n.15.

SCHMITT, R. (2005). Partidos políticos no Brasil (1945-2000). 3a Edição. Rio de Janeiro: Jorge Zahar Editor, 2005.

Skidmore, T. E. (2010). Brasil: de Getúlio a Castelo. Rio de Janeiro: Cia das Letras.

Vizentini, P. (2008. Relações Internacionais e Desenvolvimento: O Nacionalismo e a Política Externa Independente 1951-1964. Petrópolis: Ed. Vozes. 